\title{
OPTIMALISASI PERPUSTAKAAN SEKOLAH DALAM MENGEMBANGKAN MINAT MEMBACA SISWA SEKOLAH DASAR DI KOTA TERNATE
}

\section{Farida Samad}

Dosen PAUD, FKIP Universitas Khairun; e-mail; faridasamad81@gmail.com

\begin{abstract}
Abstrak
Tujuan dari penelitian ini adalah mengoptimalkan pemanfaatan perpustakaan sekolah sebagai sumber belajar serta menumbuhkan kesadaran siswa untuk gemar membaca. Tipe penelitian yang digunakan dalam penelitian ini menggunakan rancangan penelitian kuantitatif deskriptif. Penelitian ini dilakukan di 5 sekolah dasar antara lain: SDN $7 \mathrm{Kel}$ Santiong, SDN 1 Kel. Maliaro, SDN 8 Kel Santiong, SDN 6 Kel.Ngidi dan SDN $44 \mathrm{Kel}$ Dufa Dufa Kota Ternate. Subjek penelitian ini adalah siswa kelas V (Lima) dari Sekolah Dasar tersebut yang berjumlah 100 siswa. Data penelitian ini adalah minat membaca siswa serta optimalisasi perpustakaan sekolah sebagai sumber belajar. Adapun hasil yang diperoleh bahwa dari hasil analisis optimalisasi minat baca siswa SD Negeri I dan SD Negeri 6 di Kota Ternate diketahui bahwa sebanyak 40 siswa SD atau $43 \%$ siswa dengan kategori baik dan sebanyak 53 siswa SD atau 57\% dengan kategori cukup baik. Rata-rata (mean) skor responden dari hasil angket yaitu sebesar 72.49. selanjutnya, peran sekolah dalam membantu siswa dalam memanfaatkan perpustakaan sekolah antara lain: sekolah harus memberdayakan perpustakaan sekolah sebagai sumber belajar baik dengan memberikan tugas terstruktur yang datanya didapat dari referensi perpustkaan sekolah maupun dengan menggunnakan pelajaran bahasa Indonesia dengan kegiatan visit library, melengkapi koleksi bahan pustaka yang memadai yang sesuai dengan kurikulum 2013 dan bacaan yang sesuai dengan selera para siswa di sekolah dasar, memperhatikan suasana perpustakaan sekolah yang menarik, luas ruang perpustakaan, penerangan, tempat duduk yang nyaman sesuai dengan amanat UU Perpustakaan No.43 tahun 2007 serta pustakawan yang memiliki latar belakang pendidikan ilmu perpustakaan dan mengikuti pelatihan dalam perpustakaan.
\end{abstract}

Kata Kunci: Perpustakaan, Minat Baca

\section{PENDAHULUAN}

Keberadaan perpustakaan sekolah adalah sebagai tempat penelitian, tempat membaca, rekreasi, dan pusat kegiatan belajar mengajar. Juga dapat melatih siswa untuk memiliki tanggung jawab dengan cara melibatkan siswa dalam kegiatan pengelolaan perpustakaan sekolah. Seorang guru mempunyai tugas ganda, yaitu mengajar dan mendidik siswa. Mengajar mempunyai arti menyampaikan materi pelajaran sesuai dengan bidang studi yang menjadi tanggung jawabnya berdasarkan kurikulum yang berlaku. Sedangkan mendidik berarti membimbing, membantu, dan menyiapkan siswa supaya memiliki kepribadian yang baik. Bantuan dan bimbingan yang dapat diberikan guru antara lain bimbingan membaca, menelaah, dan bantuan memperoleh bahan yang berguna. Bahan bacaan itu bisa diperoleh di perpustakaan yang bukan hanya berupa buku teks pelajaran namun juga berbagai 
buku umum serta media cetak lain yang mampu memperluas wawasan siswa. Meski secara keseluruhan komponen sekolah terlibat secara langsung dalam mengembangkan perpustakaan sekolah, namun peran yang lebih penting adalah menumbuhkan minat membaca pada diri siswa. Kegemaran membaca tentunya tidak tumbuh dengan sendirinya pada diri anak. Kegemaran dan minat membaca merupakan hasil suatu proses pembinaan dan penanaman yang pada umumnya dimulai dengan pembinaan dan pengembangan minat. Di tengah kemajuan teknologi komunikasi seperti sekarang ini tentunya menawarkan berbagai pilihan.

Di satu sisi media audio visual telah memperluas cakrawala pengetahuan anak-anak, namun di sisi lain media ini tampaknya cenderung mematikan minat membaca anak. Anak-anak makin suka menonton daripada membaca. Upaya mengembangkan minat membaca anak di tengah berbagai tantangan yang begitu berat, maka peran guru bahasa sangat diperlukan. Guru bahasa memiliki hubungan yang erat dengan perpustakaan sekolah karena dia secara langsung mengajarkan cara membaca yang baik kepada siswa. Selain itu, banyak cara yang dapat dilakukan oleh seorang guru bahasa guna memotivasi siswa agar memiliki kesadaran akan manfaat membaca bagi diri sendiri. Guru dapat menceritakan sebagian isi buku dan siswa diminta untuk melanjutkan, siswa diminta untuk membuat laporan hasil bacaan, resensi buku dan sebagainya.

\section{METODE PENELITIAN}

Penelitian ini menggunakan metode kualitatif dengan rancangan jenis penelitian deskriptif. Dengan landasan berpikir bahwa penelitian ini bermaksud untuk menggambarkan keadaan atau situasi. Penelitian ini menggambarkan bagaimana mengoptimalkan perpustakaan sekolah dalam mengembangkan minat membaca siswa sekolah dasar di Kota Ternate. Penelitian ini dilakukan di 5 (lima) Sekolah Dasar di Kota Ternate yakni: SDN 7 Kel. Santiong Kota Ternate, SDN 8 Kel. Santiong, SDN 1 Kel. Maliaro Kota Ternate, SDN 6 Kel. Ngidi Kota Ternate, SDN 44 Kel. Dufa Dufa. Subjek penelitian ini adalah siswa kelas V (Lima) dari Sekolah Dasar tersebut. Data penelitian ini adalah minat membaca siswa serta optimalisasi perpustakaan sekolah sebagai sumber belajar.

Pengumpulan data penelitian ini dilakukan kuesioner, wawancara (interview), dan metode dokumenter (dokumentasi administrasi perpustakaan sekolah). Peneliti mendeskripsikan data hasil penelitian dengan rumus perhitungan rata-rata untuk mengetahui rata-rata peningkatan minat membaca siswa SD:

Keterangan:

$$
\mathrm{M}=\frac{2 x}{\mathrm{~N}}
$$

$\mathrm{M} \quad=$ mean

$\Sigma \mathrm{X} \quad=$ jumlah nilai

$\mathrm{N} \quad=$ jumlah individu 
Selanjutnya, peneliti menghitung presentase optimalisasi perpustakan sekolah dalam mengembangkan minat membaca siswa SD Kota Ternate dengan rumus penilaian.

$$
\overline{\mathrm{NP}}=\frac{k}{\mathrm{SM}} \times 100
$$

Keterangan:

$$
\begin{array}{ll}
\mathrm{NP} & =\text { nilai persen yang dicari atau diharapkan } \\
\mathrm{R} & =\text { skor mentah } \\
\mathrm{SM} & =\text { skor maksimum } \\
100 & =\text { bilangan tetap }
\end{array}
$$

Grafik 1 Kriteria Pengambilan Keputusan

\begin{tabular}{|c|l|l|}
\hline No & \multicolumn{1}{|c|}{ Interval } & \multicolumn{1}{|c|}{ Kategori } \\
\hline 1 & $81-100 \%$ & Sangat baik \\
\hline 2 & $61-80 \%$ & Baik \\
\hline 3 & $41-60 \%$ & Cukup baik \\
\hline 4 & $21-40 \%$ & Kurang baik \\
\hline 5 & $0-20 \%$ & Kurang sekali \\
\hline
\end{tabular}

\section{HASIL DAN PEMBAHASAN}

\section{Hasil Penelitian}

\section{Mengoptimalkan perpustakaan sekolah sebagai sumber belajar dalam mengembangkan minat membaca siswa}

Uraian data hasil penelitian yang telah dilakukan selama bulan september hingga november 2017 dapat difragmentasikan secara detail sebagai berikut.

Bahwa sebanyak 76 siswa atau $81.7 \%$ siswa yang senang membaca buku dimana saja berada, sebanyak 15 siswa atau $6.6 \%$ siswa SD di Kota Ternate senang membaca buku dimana saja berada, dan sebanyak 2 siswa SD atau $2.1 \%$ siswa yang senang membaca buku dimana saja berada. Data pada grafik 1.3 menunjukan bahwa 1 siswa atau $1.0 \%$ siswa kategori sering cepat bosan jika membaca, 4 siswa atau $4.3 \%$ siswa cepat bosan membaca, 35 siswa atau $37.6 \%$ siswa tidak cepat bosan dan 53 siswa atau $56.9 \%$ sangat tidak cepat bosan membaca buku. Grafik 1.4 bahwa terdapat 68 siswa atau $73.1 \%$ siswa memiliki kategori sangat sesuai, 20 siswa atau $21.5 \%$ siswa selalu bersemangat membaca buku, dan 5 siswa atau $5.4 \%$ siswa tidak sesuai. Pada grafik 1.5 bahwa jika siswa perlu nilai baik maka harus rajin membaca buku, terdapat 79 siswa atau $85 \%$ siswa sangat sesuai dengan pernyataan tersebut dan 13 siswa atau $14 \%$ siswa yang sesuai dan 1 siswa atau 1.0\% tidak sessuai. Data pada grafik 1.7 menunjukkan sebanyak 3 siswa atau 3.2\% 
pada kategori sangat sesuai, 2 siswa atau $2.1 \%$ sesuai, terdapat 16 siswa atau $17.2 \%$ tidak sesuai dan 71 siswa atau $77.4 \%$ sangat tidak sesuai bahwa siswa tidak harus membaca buku. Selanjutnya hasil pada grafik 1.8 menunjukkan 76 siswa atau $81.7 \%$ sangat sesuai dengan pernyataan, 11 siswa atau $11.8 \%$ yang sesuai, 1 siswa atau $1.0 \%$ tidak sesuai dan 5 siswa atau $5.3 \%$ sangat tidak sesuai. Grafik 1.9 menunjukkan 3 siswa atau $3.2 \%$ kategori sangat sesuai dan sesuai dengan pernyataan, 19 siswa atau $20.4 \%$ tidak sesuai dan 68 siswa atau $73.1 \%$ sangat tidak sesuai. Pada grafik 1.10 menunjukkan bahwa 1 siswa atau $1.0 \%$ kategori sangat sesuai bahwa baca buku hanya untuk siswa yang pintar saja, 3 siswa atau $3.2 \%$ sesuai, 65 siswa atau $68.9 \%$ siswa yang tidak sesuai dan 24 siswa atau $25.8 \%$ yang sangat tidak sesuai.

Selanjutnya pada grafik 1.11 menunjukkan bahwa terdapat 62 siswa atau $66.7 \%$ kategori sangat sesuai, 19 siswa atau $86.7 . \%$ sesuai, dan masing-masing 6 siswa atau $20.4 \%$ yang tidak sesuai dan sangat tidak sesuai. Grafik 1.13 menunjukkan 63 siswa atau $67.7 \%$ sangat sesuai ingin membaca buku di perpustakaan, 21 siswa atau $22.5 \%$ sesuai, 7 siswa atau $7.5 \%$ siswa yang tidak sesuai dan 2 siswaatau 2.1\% sangat tidak sesuai. Pada grafik 1.15 menunjukkan 61 siswa atau $65.6 \%$ sangat sesuai dengan pernyataan, 28 siswa atau $30.1 \%$ yang sesuai, 4 siswa atau $4.3 \%$ tidak sesuai dengan pernyataan. Pada grafik 1.16 menunjukkan bahwa sebanyak 4 siswa atau $4.3 \%$ pada kategori sangat sesuai, 9 siswa atau $9.7 \%$ sesuai, terdapat 13 siswa atau $13.9 \%$ tidak sesuai dan 67 siswa atau $72 \%$ sangat tidak sesuai bahwa buku komik lebih menarik daripada buku pelajaran. Data pada grafik 1.18 menunjukkan 1 siswa atau $1.0 \%$ sangat sesuai mengisi waktu luang dengan main daripada membaca buku, 54 siswa atau 58\% sesuai, 22 siswa atau $23.6 \%$ siswa yang tidak sesuai dan 64 siswa atau $68.8 \%$ yang sangat tidak sesuai. Grafik 1.20 menunjukkan 69 siswa atau $74.1 \%$ kategori sangat sesuai, 19 siswa atau $20.4 \%$ siswa sesuai bahwa setiap waktu luang merka perlu membaca, 3 siswa atau $3.2 \%$ tidak sesuai dan 2 siswa atau $2.1 \%$ sangat tidak sesuai. Pada grafik 1.22 menunjukkan 18 siswa atau $18.7 \%$ sangat sesuai mendatangi perpustakaan yang lebih lengkap dari perpustakaan yang ada di sekolah, 12 siswa atau 13\% siswa sesuai, 36 siswa atau $38.7 \%$ yang tidak sesuai dan 27 siswa atau $29 \%$ siswa yang sangat tidak sesuai. Pada grafik 1.23 menunjukkan sebanyak 8 siswa atau $8.6 \%$ siswa pada kategori sangat sesuai, 17 siswa atau $18.2 \%$ sesuai, terdapat 52 siswa atau $56 \%$ tidak sesuai dan 16 siswa atau $17.2 \%$ siswa sangat tidak sesuai bahwa bacaan yang ada di perpustakaan sekolah sudah cukup bagi mereka. Pada grafik 1.24 bahwa 25 siswa atau $26.8 \%$ sangat sesuai ingin mendapatkan buku-buku terbaru, 55 siswa atau $59.1 \%$ sesuai, 4 siswa atau $4.3 \%$ siswa yang tidak sesuai dan 9 atau $9.7 \%$ yang sangat tidak sesuai. Pada grafik 1.26 menunjukkan bahwa 3 siswa atau 3.2\% sangat sesuai mencari sumber bacaan dari internet daripada buku pelajaran, 9 siswa atau $9.7 \%$ sesuai, 43 siswa atau $46.2 \%$ siswa yang tidak sesuai dan 38 siswa atau $40.8 \%$ yang sangat tidak sesuai. Dengan demikian, hasil analisis optimalisasi minat baca siswa Negeri 
I dan SD Negeri 6 di Kota Ternate diketahui bahwa sebanyak 40 siswa atau 43\% siswa dengan kategori baik dan sebanyak 53 siswa SD atau 57\% dengan kategori cukup baik. Rata-rata (mean) skor responden dari hasil angket yaitu sebesar 72.49.
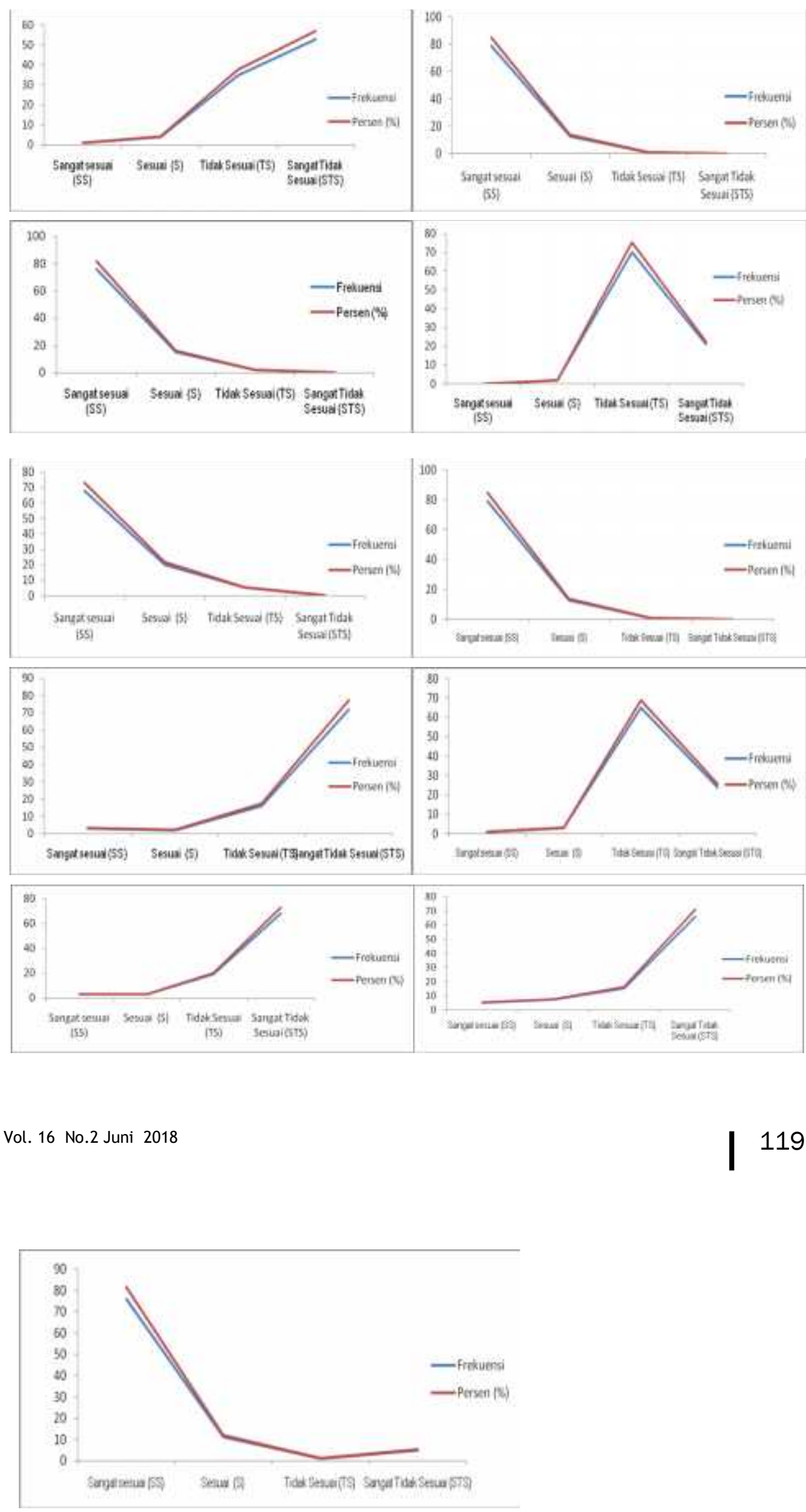

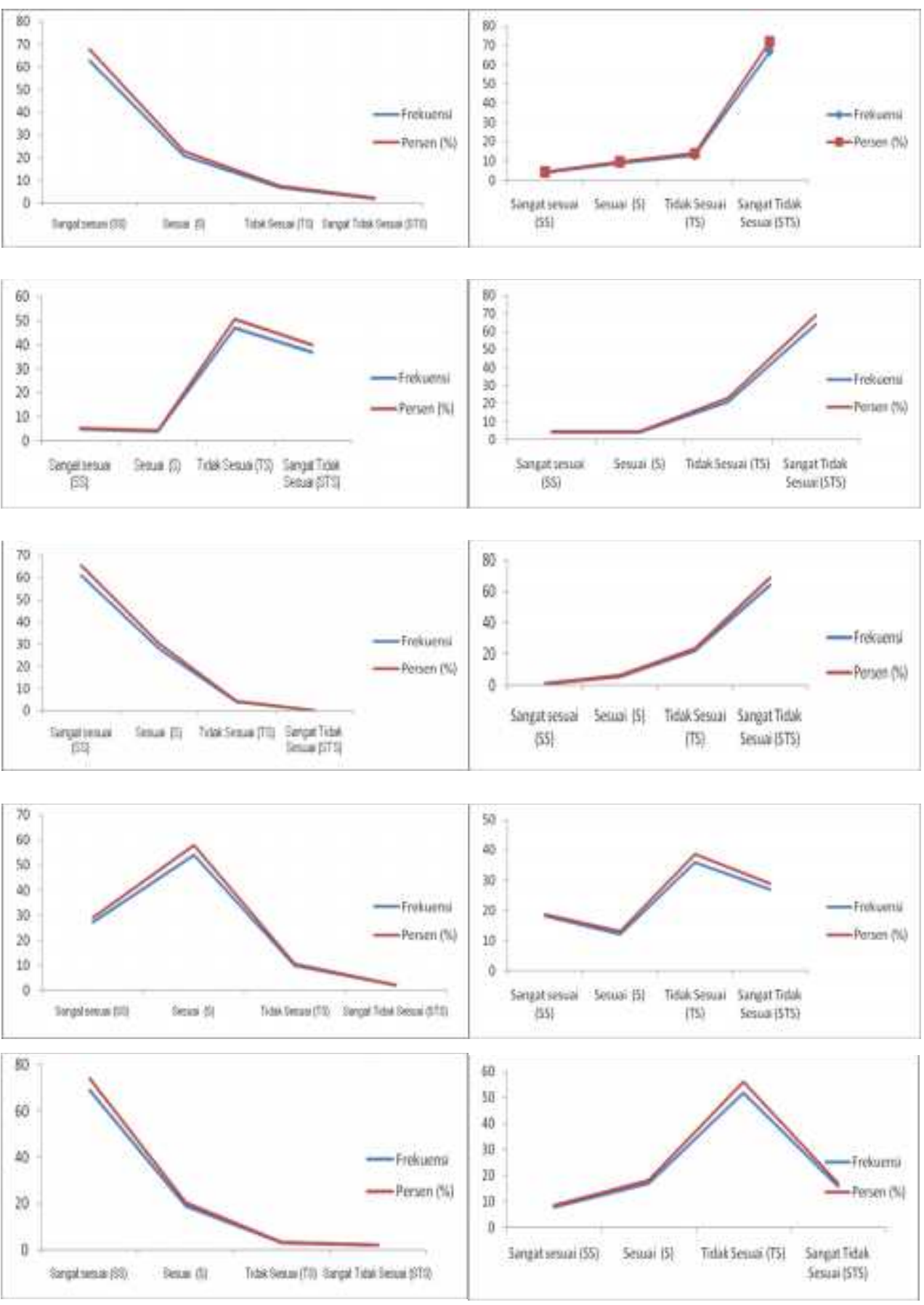

Vol. 16 No.2 Juni 2018 

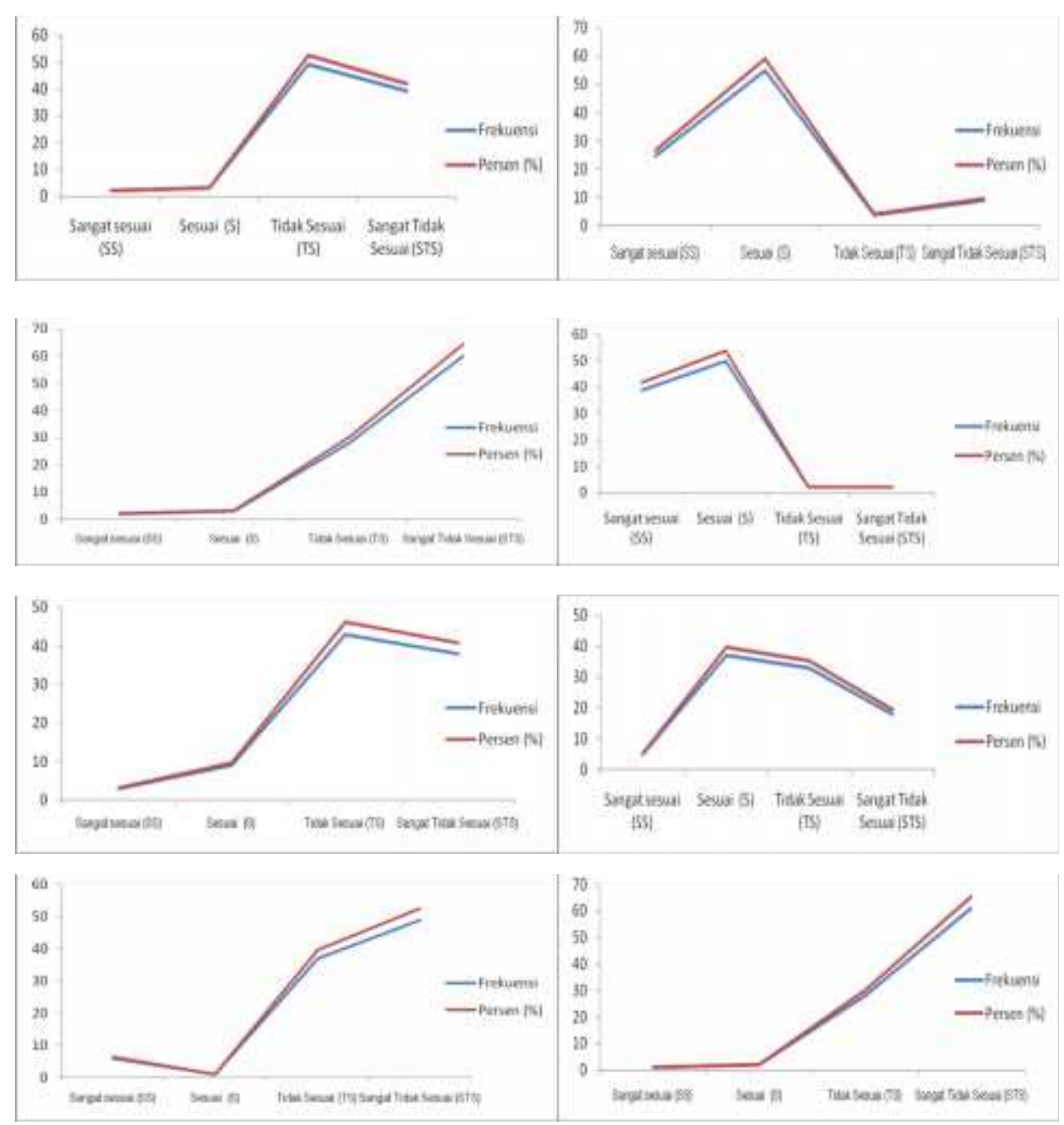

\section{PEMBAHASAN}

Perpustakaan sekolah menyediakan berbagai informasi dan ide yang merupakan dasar keberhasilan masyarakat masa kini yang berbasis pengetahuan dan informasi. Salah satu syarat mutlak bagi siswa sekolah untuk dapat menggunakan perpustakaan adalah mereka harus bisa membaca dan mempunyai minat baca. Semua bahan pustaka dalam bentuk apapun pada umumnya berisi huruf, angka dan gambar yang disusun dalam suatu bahasa tertentu dan menarik perhatian pembacanya biasanya huruf, angka dan gambar disusun dengan lay out yang menarik, dibuat berwarna-warni, dibuat tebal dan tipis dan lain sebagainya 
agar memudahkan pembaca memahami isi/maksud dari yang tertulis. Keberhasilan dalam belajar sebagian besar ditunjang oleh minat baca. Sebagai salah satu kebutuhan hidupnya sehingga tercipta masyarakat yang senang membaca. Namun demikian, secara umum minat membaca siswa di SD Negeri 1 Kota Ternate dan SD Negeri 6 Kota Ternate termasuk dalam kategori cukup baik. Hal ini ditunjukan dengan data angket bahwa angka 57\% siswa cukup memiliki keinginan untuk membaca di perpustakaan sekolah. Namun setelah peneliti telusuri lebih jauh bahwa ternyata siswa kurang memiliki minat untuk membaca hal ini sebagaimana dinyatakan oleh mereka bahwa "membaca biasanya karena akan ujian". Pernyataan ini juga dikuatkan oleh petugas pustakawan di SD Negeri 1 Kota Ternate oleh bapak DJ pada saat wawancara bahwa pada saat tugas sekolah atau menjelang ujian sekolah terdapat 30-40 siswa yang berkunjung di perpustakaan. Ketika dilakukan observasi di lapangan, siswa yang mengunjungi perpustakaan tergolong tinggi dengan ukuran ruang perpustakaan yang tidak terlalu luas. Dilihat dari pernyataan tersebut akses siswa terhadap buku-buku cukup dan ini mengindikasikan motivasi yang cukup pula terhadap kegiatan membaca. Membaca untuk siswa SD menjadi suatu keniscayaan, maka setiap hari mereka menjadwalkan sebagian waktunya untuk membaca di perpustakan. Sebagaimana diungkapkan oleh salah seorang siswa bahwa "dengan membaca saya mendapatkan banyak pengetahuan dan wawasan, selain itu kita sebagai siswa dituntut untuk selalu membaca, ada atau tidak ada ujian". Siswa tersebut juga mengungkapkan jika dirinya memiliki jadwal tetap untuk membaca "setiap harinya paling tidak 1-2 jam jadwalkan untuk membaca buku.

Seiring waktu dengan nilai akreditasi sekolah -A- sekolah ini terus berbenah melengkapi sarana perpustakaan. Petugas perpustakaan belum memiliki kompetensi yang sesuai dengan kompetensinya karena bapak DJ hanya berijazah lulusan SMA. Hal ini berbeda dengan petugas perpustakaan di SD Negeri 6 Kota Ternate bahwa ibu DH lulusan diploma ilmu perpustakaan dari Universitas Terbuka. Tentang jumlah buku yang ada di perpustakaan SD Negeri I Ternate terdapat kurang lebih 10.000-an buah buku untuk semua mata pelajaran dan dapat diakses di perpustakaan. Selain itu juga terdapat beberapa sumbangan buku-buku yang bersumber dari DAK, Hibah Bank Mandiri, Dinas Pendidikan Kota Ternate, dan Balai Bahasa serta mengikuti perkembangan buku-buku terbaru dilihat dari aktivitas para siswa di sekolah yang memanfaatkan sarana sumber belajar di perpustakaan. Sedangkan di perpustakaan SD Negeri 6 Kota Ternate terdapat hanya 3000-an buah buku untuk semua mata pelajaran di SD hanya saja bentuk sumbangan hanya berasal dari DAK dan penerbit Erlangga. 

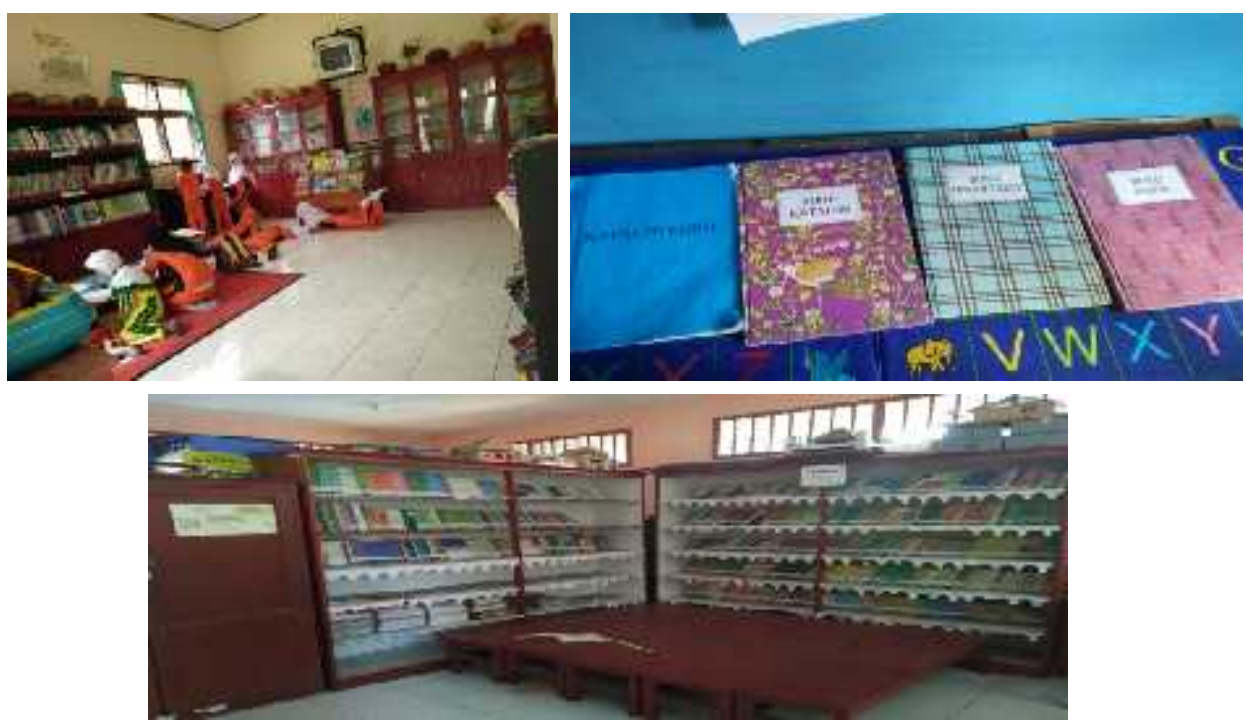

Gambar 1. Perpustakaan SDN 6 Kota Ternate

Dalam menerapkan strategi pembelajaran, pemanfaatan untuk aktivitas belajar di perpustakaan sekolah harus melibatkan juga pihak guru dalam menyiapkan mental siswa di kedua sekolah tersebut agar berinteraksi dengan bahan pustaka dan aktivitas yang dipilih, memberikan bimbingan selama kegiatan berlangsung, memberikan penilaian atas hasil yang dicapai siswa sehingga dapat memotivasi siswa yang lain untuk mendapatkan prestasi. Karena keberhasilan sekolah tidak mudah didapatkan jika tidak diikuti kerja keras dan minat yang tinggi, yaitu salah satunya adalah dengan minat membaca. Guru harus dapat merangsang dan memberikan dorongan untuk memunculkan potensi siswa dalam hal membaca. Salah satu cara untuk memotivasi siswa dalam belajar adalah membangkitkan minat siswa. Oleh karena itu, upaya peningkatan minat dan kebiasaan membaca juga diadakan di sekolah melalui keberadaan perpustakaan. perpustakaan merupakan faktor yang mempengaruhi minat baca siswa. Perpustakaan sebagai sumber belajar yang diharapkan dapat menumbuhkan minat baca bagi siswa, maka hendaklah dikelola secara baik, misalnya sistem komputerisasi yang dapat memudahkan siswa dalam mencari judul buku yang diinginkan. Perpustakaan yang baik harus bisa memberikan suasana yang nyaman dengan selalu menjaga kebersihan, menjaga kerapian buku, serta penataan tempat baca yang bisa membuat siswa nyaman un tuk berla ma-lama di perpustakaa. Suasana yang nyaman serta mampu menarik mina siswa membaca di perpustakaan sekolah. 


\section{SIMPULAN}

Kesimpulan penelitian ini antara lain:

1. Hasil analisis hasil analisis optimalisasi minat baca siswa SD Negeri I dan SD Negeri 6 di Kota Ternate diketahui bahwa sebanyak 40 siswa SD atau 43\% siswa dengan kategori baik dan sebanyak 53 siswa SD atau 57\% dengan kategori cukup baik. Rata-rata (mean) skor responden dari hasil angket yaitu sebesar 72.49.

2. Peran sekolah dalam membantu siswa dalam memanfaatkan perpustakaan sekolah antara lain: sekolah harus memberdayakan perpustakaan sekolah sebagai sumber belajar baik dengan memberikan tugas terstruktur yang datanya didapat dari referensi perpustkaan sekolah maupun dengan menggunnakan pelajaran bahasa Indonesia dengan kegiatan visit library, melengkapi koleksi bahan pustaka yang memadai yang sesuai dengan kurikulum 2013 dan bacaan yang sesuai dengan selera para siswa di sekolah dasar, memperhatikan suasana perpustakaan sekolah yang menarik, luas ruang perpustakaan, penerangan, tempat duduk yang nyaman sesuai dengan amanat UU Perpustakaan No.43 tahun 2007 serta pustakawan yang memiliki latar belakang pendidikan ilmu perpustakaan dan mengikuti pelatihan dalam perpustakaan.

\section{DAFTAR PUSTAKA}

Budarvari, S., Windholz, M., and Stroumtsos, L. Y.m., 1989., The Merk Index: An Encyclopedia of Chemical, Drugs, and Biological, $11^{\text {th }}$ ed, Merk \& Co. Inc., New Jersey, New York.

Burton, G. A., Pitt, R. E. 2001. Stormwater Effects Handbook; A Toolbox for Watershed Managers, Scientists, and Engineers. Lewis Publishers, New York.

Canter,W.Larry.,1977, Environmental Impact Assesment., McGraw-Hill, Inc., University of Oklahoma.

Greenberg. A.E., Rand. M.C., and Taras, M.J., 1992., Standard Methods for The Examination of water and Wasterlvald"., Eighteen Edition, 5-33-5-38., American Public Health Association., Washington, DC.

Haslam, S.M, 1992. River Pollution; An Ecological Perspective. Belhaven Press, London, UK

Hendzel, M.,R., and Johnson, D.M., 1976., Determination of Mercury in Fish., Anal. Chem, 48, 926-928.

Horne, R. A. 1978., The Chemistry of Our Environmental. Jon Willy \& Sons, New York, Chienester, Bristone. Toronto. 
Kupchella C.E dan M.C. Hyland. 1993. Environmental Science, Living Within The System of Nature. Prentice Hall, New Jersey, USA.

Lawrence.,K.C., White. M. Potts. RA., and Bertrands. R.D., Cold Vapour Determination of Mercury., Anal. Chem, 52 1391-1392

Markert.,B.,1994., Environmental Sampling for Trace Analysis, VCH, Verlagsgesellschaff, mbH, Germany.

Mitchell. Bruce., Setiawan. B., Rahmi. H. Dwita., 2007, Pengelolaan Sumber Daya dan Lingkungan, Gadjah Mada University Press, Yogyakarta.

Morita, Yushinaga, Edmonds, The Determinations of Mercury Species in Environmental and Biological Samples., Technical Report. National Institute for Environmental Studies, 16-2 Onogawa, Tsukuba, Ibaraki 305, Japan.

Oda and Ingle.,J.D., 1981, Specification of Mercury by Cold Vapor Atomic Absorption Spectrometry with Selective Reduction, Anal. Chem., 53. 23052309

Suhendrayatna, 2001, Heavy Metal Bioremoval by Microorganism: A Literature Study, Applied Chemistry and Chemichal Engineering. 1, 1-9.

Zhao, Jing-Zhu, Liu Yang, Ke-Ming Ma, Xue Bai, and Qing-Hai Guo., 2007, The Relationship of Urbanization to Surface Water Quality in Faour Lakes of Hanyang, Cina International Journal of Sustinable Defelopment and World Ecology, London. 